\title{
Poststructuralism, Discourse and Problematization: \\ Implications for \\ Implications for
gender mainstreaming
}

\section{By CAROL BACCHI}

Gender mainstreaming programs are proliferating worldwide.

How are we to assess their potential benefits and possible limitations? This article introduces a tool to assist in this analysis. 
process of continuous interrogation of conceptual premises in all policies and policy proposals, including one's own, with the objective of devising proposals that come as close as possible to desired political objectives. A case study on gender mainstreaming explains potential uses of the approach for those involved in planning gender mainstreaming programs.

\section{'WHAT'S THE PROBLEM REPRESENTED TO BE?' POSTSTRUCTURAL CRITICAL POLICY ANALYSIS}

A WPR approach to policy analysis promotes inquiry into the commonplace assumptions or presuppositions that lodge within policies and policy proposals. The objective is to uncover 'unexamined ways of thinking' that lie behind the policies put in place to govern (Foucault 1994:456) as a step towards imagining how we could be governed differently (Pavlich 2001).

The most direct route to uncovering the grounding premises and assumptions - the 'thinking' - within policies is to focus on how they problematize an issue (Foucault 1997). That is, since every policy endorses change of some sort, every policy contains an implicit representation of what is seen to be problematic (which I call a problem representation). Asking 'what's the problem represented to be?' opens up this 'thinking' to critical scrutiny.

Conventionally we tend to think about policies as addressing or as responding to concrete social 'problems' that are readily identifiable, such as the currently topical 'obesity problem'. Shifting the focus to the process of problematization allows us to see that all policies, by their very nature, always give 'problems' a particular shape. For example, a government-funded media campaign to encourage children to become more active constitutes or creates the 'problem' of 'childhood obesity' as a 'problem' of inactive, possibly media-obsessed, young people. By contrast a policy banning fast- food advertising during children's TV programs constitutes the 'problem' to be aggressive, and possibly unethical, advertising practices.

Note that the suggestion here is not that politicians, bureaucrats or other members of the policy community devise specific ways of representing policy 'problems'. The analysis performed in a WPR approach does not work at the level of conscious shaping of arguments or of competing problem definitions that lead to different 'solutions' (Bacchi 1999: 34-36). Rather the goal is to discover deep-seated ontological and epistemological commitments within policies ('solutions') that are probably hidden to policy makers and planners. For example it encourages identification of the 'expert knowledges' upon which problem representations rely, and hence recognition of the place of those knowledges in regulating social order. As Beilharz (1987: 393 ) describes, 'the objective becomes that of seeking to understand policy better than its authors'.

Problematizations and the problem representations they contain are constituted in discourse. Discourse, in a WPR approach, refers to relatively bounded, socially produced forms of knowledge that set limits upon what it is possible to think, write or speak about a 'given social object or practice' (McHoul and Grace 1993: 31, Bacchi 2005, 2009b). Some discourses have greater status than other discourses. These tend to be those that are institutionally sanctioned and that reinforce established economic, legal, familial, religious and educational norms. Contestation nonetheless remains possible because discourses are plural, complex and, at times, internally inconsistent. Hence, they both constrain and enable. In Foucault's (1972: 120) words, discourse is an 'asset', 'by nature, the object of a struggle, a political struggle'.

In this understanding policies, through the discourses on which they rely, create certain possibilities for being - 'subject-po- 
sitions and subject-functions' (Foucault 1991: 58) - which political subjects (are impelled to) take up, an idea captured in the analytic category of 'subjectification effects'. Importantly, subjectification - taking up subject positions - is an incomplete process. Policies do not determine subject positions; they elicit them, creating the possibility for resistance (Dean 1999: 32). The plurality of discourses produces a plurality of subject positions, as do practices 'from below', which are themselves constitutive (Petersen 2003: 198).

Different representations of the 'problem' (problem representations) have a range of effects, influencing what gets done, what is ignored or downplayed, and how people feel about the issue, about themselves and about others. As Shapiro (1988: ix) explains, 'representations do not imitate reality but are the practices through which things take on meaning and value'. In terms of critique, therefore, it is held to be inadequate simply to identify a proliferation of competing problem representations. Rather, the goal is to recognise that problem representations, as interventions 'in the real', have uneven effects on specific groups of political subjects and to reveal the mechanisms by which this occurs. The WPR approach therefore counters a relativist presumption that any one 'truth' is as good as any other (Bacchi 1999:38-39). Rather, a key objective becomes considering possible limits in the ways in which certain 'problems' are produced, and an inventive imagining of other forms of problematization. As with Foucault, the 'perspective affirmed is that of those who resist' (Simons 1995: 91).

A WPR approach to policy analysis consists of six questions (see chart below) designed to probe how policies represent the 'problems' they appear or claim to address - examining the taken-for-granted thinking that underpins problem representations, and the effects that accompany them. It identifies three interconnected, and over- lapping kinds of effects that need to be 'weighed up':

- Discursive effects: effects that follow from the limits imposed on what can be thought and said;

- Subjectification (or 'subjectivisation') effects: the ways in which subjects and subjectivities are constituted in discourse;

- Lived effects: the ways in which problem representations within policies directly affect people's day-to-day lives and socially-embedded bodily possibilities, 'making live' and 'letting die'.

(Rabinow and Rose 2006:203, Dean 2006)

Because problem representations tend to be embedded within multiple layers of meaning, the approach involves more than a 'one-off' exercise. It requires the repeated application of the six questions at different stages of the analysis.

The WPR approach includes a directive (at the bottom of the six questions) to apply the questions to one's own policy proposals. This directive is meant to alert analysts and planners to the possibility, and indeed to the likelihood, that their own proposals may well unintentionally incorporate potentially problematic presuppositions 'unexamined ways of thinking' - that require critical reflection.

\section{WHAT'S THE PROBLEM REPRESENTED TO BE?}

AN APPROACH TO POLICY ANALYSIS

1. What's the 'problem' (e.g. of 'problem gamblers', 'drug use/abuse', 'gender inequality', 'domestic violence', 'global warming', 'child sexual abuse', etc.) represented to be in a specific policy?

2. What presuppositions or assumptions underlie this representation of the 'problem' (called a 'problem representation')?

3 . How has this representation of the 'problem' come about?

4. What is left unproblematic in this problem representation? Where are the silences? Can 
the 'problem' be thought about differently? 5 . What effects are produced by this representation of the 'problem'? Consider discursive effects, subjectification effects and lived effects.

6. How/where has this representation of the 'problem' been produced, disseminated and defended? How could it be questioned, disrupted and replaced?

Apply this list of questions to the problem representations within one's own policy proposals. (Adapted from Bacchi 2009a: 48)

The following case study on gender mainstreaming initiatives in Ireland and the Netherlands indicates the sorts of questions and perspectives provoked by using a WPR approach to policy analysis.

\section{EXEMPLAR: GENDER MAINSTREAMING ${ }^{1}$}

Gender mainstreaming is a relatively recent development in equality policy that recommends examining all policies for their gender-sensitivity and gender-inclusiveness. With its origins in the development field, it is currently in vogue across Europe and in international organizations such as the World Bank, the IMF (International Monetary Fund) and the ILO (International Labour Organization). It is also growing in popularity in parts of Asia (Bacchi 2009c). A large number of policy activists and public servants worldwide are currently involved in planning gender mainstreaming initiatives. A common trend is to introduce guidelines - called in different places 'gender analysis', 'gender proofing' or 'gender impact assessment' - which prescribe a methodology for checking if policies adequately incorporate a 'gender perspective'.

The rapid development of gender mainstreaming initiatives has been accompanied by fervent debate about the prospects for the reform. While some authors conjecture that the popularity of gender mainstreaming may reflect the ease with which it suits a market-driven, neo-liberal emphasis on women's 'productive' role (Rönnblom 2008), others are more optimistic about its transformative potential (Rees 1998). It is also unclear how the new approach is designed to 'sit' in relation to earlier equality policies, specifically positive/affirmative action. In some places the turn to mainstreaming has been used to justify removing forms of positive action on the grounds that, since women's needs are now 'mainstreamed', women no longer require specific, targeted policy initiatives. The same grounds have been used in other places to remove Women's Policy Units, or to reduce their funding and influence (Osborne et al. 2008: 149). How then are we to assess gender mainstreaming as a reform initiative? How are those involved in developing gender mainstreaming initiatives to reflect upon the proposals they put forward?

The suggestion accompanying a WPR approach is to treat gender mainstreaming as a contested concept, or more precisely as a field of contestation, shaped by on-theground political deliberations and practices, including discursive practices that produce specific ways of understanding the 'problem' of 'gender inequality' (Bacchi and Eveline 2003, Bacchi and Eveline 2010). This perspective makes it unwise to declare, in advance, that gender mainstreaming represents some new breakthrough in gender equality thinking. Rather, the suggestion is to look at specific proposals to see how they constitute or shape the 'problem' of 'gender inequality'. The goal is to bring the deep-seated understandings underpinning these proposals into open discussion in order to reflect upon their relative usefulness and possible limitations.

It is important here to recognise that there is no suggestion that members of the policy community deliberately devise particular ways of understanding gender inequality. Rather, specific proposals incorporate such understandings at deep-seated and largely unconscious levels. This is why it is 
necessary to develop tools to uncover them.

A WPR approach offers one such tool. The following sections use the questions in the approach to compare 'gender proofing' in Ireland and 'gender impact assessment' in the Netherlands. Parenthetical references to Question 1, Question 2, etc. signal when a specific question in the WPR approach has been applied (see chart above).

\section{Gender Mainstreaming in Ireland}

At the most basic level, in Irish 'gender proofing' the 'problem' of 'gender inequality' is linked to the 'differences' in the lives of women and men (Question 1). Those applying the approach are instructed to: 'Keep it simple! The differences in the lives of women and men, in particular those which contribute to inequalities, are part and parcel of everyday experiences' (Crawley and O'Meara 2002:20). To establish the nature of these 'differences', there are instructions to 'Gather any available gender disaggregated statistics, facts and information being addressed by the action/objective' (Crawley and O'Meara 2002:19). Policies then need to be devised to respond to those identified 'differences'. This 'differences' model of gender mainstreaming is the dominant model in many countries and in multi-national organizations (Bacchi 2004).

A fairly conventional distinction between 'biological' sex and 'cultural' gender differences underpins this 'differences' understanding of the 'problem' of 'gender inequality' (Crawley and O'Meara 2002: 6; Question 2). 'Sex' as biology is distinguished from 'gender' as social attributes, norms and behaviours. In this understanding gender becomes a cultural cloak to be removed in order to allow 'women' to be 'equal'. This perspective is linked to a basic equal opportunity premise - that women's abilities have been judged falsely because of stereotypes and that these 'cultural' stereotypes need to be overthrown because some women (it is argued) can be like men (Bacchi 1990).

Hence, 'gender proofing' accepts and works within the basic premises of a hegemonic equal opportunity discourse (Questions 2 and 3; Polverari and Fitzgerald 2002a: 4). We are left with the impression that the 'problem' is inherent differences within some women (those who fail to become 'equal') that need to be accommodated, rather than systemic factors that produce some 'differences' as disadvantages and others as advantages (Eveline 1994, Question 4). As a result the approach naturalizes and neutralizes issues of politics and of power (Question 4).

Without diminishing the significance of this challenge to the assumption that women are destined by biology to confine their activities to the 'domestic sphere', it is relevant to ask what does not get problematised in this representation of the 'problem' (Question 4). In this explanation, for example, it becomes difficult to put in question the masculine norms of the workplaces to which women are demanding access, norms which reinforce the marginalisation of women and hence which reproduce gender as a relation of inequality.

Illustrating this point, the Irish mainstreaming agenda is described as gender neutral. The Gender Proofing Handbook (Crawley and O'Meara 2002: 8-9) states explicitly that 'gender proofing' is 'premised on recognition that inequalities exist which can and do discriminate against either sex' (see also Polverari and Fitzgerald 2002a: 1). As exemplars the Handbook highlights the need for 'more emphasis' on men's health and men's right to paternity leave entitlements. Social services are criticized for being 'geared towards women' with 'no alternative or complementary supports for men'. This supposedly 'evenhanded' approach includes men in 'gender' in a depoliticised way, denying the unequal power relations between women and men, 
and ignoring the normative status ascribed to masculine characteristics (Question 4).

While representing the 'problem' in gender-neutral terms might be interpreted to be part of a strategic framing exercise to win over men supporters (Verloo 2005), in effect gender neutrality follows logically the understanding of the 'problem' as identifiable statistical differences in the experiences of women and men, 'differences' that must be 'evened out' (Question 5). That is, gender neutrality follows the conceptual logic informing a 'differences' approach (Question 2). Very different issues arise if we ask, for example, how primary responsibility for nurture of the young becomes a 'difference' about women that serves specific advantages for those who are most like men are meant to be (Question 4).

A detailed example from the Gender Proofing Handbook indicates the 'thinking' behind gender analysis in Ireland. In a sample from a training session on how to 'develop geographically spread affordable workspace, in a range of sizes (and areas)', the following 'different experiences and roles of men and women' are identified under Step 1 of the approach:

a. Women work in the home, managing people, finance, resources. They may lack confidence or self-belief in relation to enterprise. Women may have little experience of structured employment or of managing adults. Men have greater experience of structured employment and experience of risk taking with a work situation outside the home.

b. Women assume primary responsibility for child rearing.

c. Women are less likely to have transport available to them.

d. Women are seen to be more vulnerable to physical attack.

e. Women's prior experience of sourcing finance may have been negative.

(Crawley and O'Meara 2002: 24)

I have singled out three proposals to illus- trate how each represents (and hence creates) the 'problem', the presuppositions that underpin this problem representation, and the range of effects that accompany it:

a. 'Unless proactive measures are taken to address the lack of previous experience and/or confidence for women, they are unlikely to be in a position to avail of the workspace'.

b. 'There is a need for childcare in the centre or immediate area to make it accessible to women.'

c. 'Ensure design is safety conscious (i.e.

lighting, personal security system)'.

(Crawley and O'Meara 2002: 25)

Applying Question 1 of the WPR approach, 'proactive measures' taken 'to address the lack of previous experience and/or confidence of women' represent the 'problem' to be women's lack of experience or confidence. Question 2 encourages us to think about underlying assumptions. Here for example it is assumed that women have some form of deficiency. They are set up as the 'problem', as the ones who need to change. The notion of confidence, moreover, relies upon a particular understanding of psychological development, with psychology one of the grounding 'expert knowledges' that need to be identified and interrogated.

Question 3 in a WPR approach requires a close examination of the development of this proposal, how it came to prominence. For example, it would be relevant to consider the pressures in Ireland at a particular point in time to become 'competitive' and 'productive', and how these pressures affect the shape of the proposal.

Question 4 requires that we reflect upon the issues that could be raised but that are silenced by this representation of the 'problem'. This challenging task involves broadening one's perspective through reading widely about developments elsewhere. One possible insight here is that seeing women's lack of confidence as responsible for their exclusion from specific worksites makes it 
difficult to draw attention to the character of those worksites. The competitive environment of the workplace is not problematized.

Question 5 invites reflection on the implications or effects that might flow from this representation of the 'problem'. A key discursive effect has already been identified - the silencing of any substantive critique of the worksites themselves. To think about subjectification effects, we need to reflect upon how drawing attention to women's supposed 'lack of confidence' might make the women involved think about themselves and how it might make others think about them. Finally, in terms of lived effects, we would want to reflect upon the ways in which this proposal impacts on the work prospects and standards of living of the women concerned. Question 6 looks specifically to the ways in which this representation of the 'problem' is reinforced through dissemination and repetition, and seeks to uncover contesting views.

The point of this kind of exercise is not to say that a proposal is incorrect or misguided. It is completely possible that some women do 'lack' 'confidence'. However, we need to probe this apparently straightforward proposition for the unexamined 'ways of thinking' that underpin it. The goal is to open up a space for critique and reflection, encouraging a willingness to scrutinize commonly accepted concepts and belief systems.

As another example, the proposal to provide childcare facilities on site, to 'make it accessible to women' (see above), represents the 'problem' to be 'caring responsibilities' (Question 1), here designated as women's responsibilities (Question 2). Question 3 encourages us to reflect on the specific working arrangements that have led to women assuming responsibility for most child and other care. Question 4 asks us to reflect on what is not problematized in such a proposal, here the assumption that care is a 'problem', an extraneous factor that can be attended to in order to increase productivity. Question 5 alerts us to the way in which this proposal assumes heterosexual pairing, reinforcing the categories of 'man' and 'woman'. Question 6 draws our attention to the many feminist interventions aimed at increasing men's contribution to caring roles.

The same form of analysis could be applied to the proposal that better lighting would produce a 'safety conscious' work site. Here the 'problem' of violence against women is represented to be a matter of situational opportunity (Question 1), assuming that violent crime is a rational decision of self-interested actors (Question 2, Bacchi 2009a: 103).

Gender Impact Assessment in the Netherlands offers useful points of contrast to Irish 'gender proofing', as discussed below.

\section{Gender Impact Assessment \\ in the Netherlands}

In the Dutch approach to gender analysis, called EER (Emancipation Impact Assessment), the 'problem' is explicitly identified, not as 'differences' between men and women, but as 'unequal power relations between men and women' (Question 1). Three structures are identified as central to the operation of those relations: the gendered division of labour, the organization of intimacy and the organization of citizenship. Two processes are described as pivotal to the reproduction of those structures: the distribution of resources, and the operation of rules (interpretations or norms) about or connected to gender (Verloo and Roggeband 1996, Verloo 2001). The Dutch approach also includes criteria as normative grounds for assessing whether a situation is to be judged positively or negatively: equality, autonomy and pluriformity/diversity.

In contrast to 'gender proofing' in Ireland, the focus in the Netherlands is on the impact of policies on 'gender relations' rather than their impact on men and women as presumably fixed categories of 
people. 'Gender' is understood, not as a characteristic (or attribute) of people nor as a cultural cloak to be removed, but as a political process (Question 2), necessarily involving power. This shift in representation of the 'problem' has important effects (Question 5). For example:

- Identifying the 'gendered division of labour' as a structure of inequality means that, rather than inserting women into existing or slightly modified work structures as in Ireland, it becomes possible to put men's contribution to domestic labour on the agenda.

- Highlighting the 'organization of intimacy' as central to gender inequality puts aspects of people's so-called private lives on the agenda. Violence, for example, is viewed as a product of unequal gendered power relations, rather than as a matter of situational opportunity, as in Irish 'gender proofing' (see discussion above).

- The explicit targeting of the 'organization of citizenship' as a structure of inequality puts any presumed gender-neutral understanding of citizenship in question.

The focus on unequal power relations between men and women means that, in the Netherlands, men enter the analysis, not as a statistical category to be set in comparison with 'women' as in Irish 'gender proofing', but as 'gendered beings', whose behaviours need to change when those behaviours reinforce asymmetrical power relations (Question 2). This understanding of the 'problem' is potentially transformative since it challenges the masculine norms that characterise mainstream institutional practices (Question 5). Shifting the focus from 'gender' as a part of people to gender as political process also creates the opportunity to examine the impact of gendered assumptions on the maintenance of hierarchical social relations beyond those between 'women' and 'men' (i.e. including social relations around 'race'/ethnicity, class, sexuality and disability).

\section{Discussion}

Above I have used the questions in the WPR approach to draw attention to points of contrast between the Irish and the Dutch approaches to gender analysis. The goal, as mentioned earlier, is not to condemn any specific proposal but to open up a space for critique and reflection on underlying presuppositions and their political implications. To this end it is useful to note that neither the Irish nor the Dutch framework appears to be sufficiently sensitive to the productive or constitutive dimension of policy, highlighted in the WPR approach. Both in effect are reactive models, seen for example in the very language of 'impact assessment'. To shift the focus to policies as productive or constitutive practices, we need to examine how specific policy proposals produce and reinforce gender categories and particular forms of gender relations.

Two examples from Irish 'gender proofing' illustrate this point. Representing the 'problem' to be deficiencies in women's character (lack of confidence) or experiences constitutes women as the 'problem', reinforcing the cultural location of women as outsiders. So, too, representing the 'problem' to be women's lack of access to child care facilities reinforces the assumption that the domestic division of labour and the heterosexual family are unchangeable facets of life rather than the constraints of a particular form of economic organization. In effect then these proposals reinforce existing gender categories.

Consider also the 'gender impact assessment' performed on the 1996 Dutch General Social Assistance Act (1996 in Plantenga 2000). The Act placed an emphasis on what was called the 'activating effect' in the labour market, the imperative to engage as many people as possible in paid labour. The obligation to work, or at least to apply for work, was extended to lone mothers with children five years old or over. A GIA (Gender Impact Assessment) concluded 
that for most women the new Act meant an improvement.

Analysing this policy using the WPR approach produces a very different assessment. It directs attention to the way in which representing the 'problem' to be peoples' (in this instance single mothers') absence from paid labour (Question 1) privileges an economic understanding of worth (Question 2) and ignores the care needs of the population (Question 4). It also highlights how such a problem representation reinforces existing gender relations (Question 5). As Plantenga (2000:9) argues, so long as there is no 'national framework for care' to accompany the 'national framework of a general obligation to work', women will continue to be expected to provide such care.

As illustrated here, the goal of a WPR approach is to draw attention to the productive role of policies - how they are discursive practices that shape and reinforce the categories of 'men' and 'women', and other social actors and social relations. Elsewhere my colleague, Joan Eveline and I (Eveline and Bacchi 2005, Bacchi and Eveline 2010) describe policies as gendering practices, to highlight this constitutive dimension of policies. Following this line of thinking it may be useful to describe policies as 'classing', 'racializing', 'disabling' and 'heteronorming' practices. Shifting the focus from presumed fixed categories of people to the practices that constitute such categories may also provide a way forward in attempts to theorize 'intersectional' relationships (Yuval-Davis 2006, Bacchi and Eveline 2009).

\section{CONCLUSION}

The kind of poststructural approach to policy analysis offered here starts from the premise that, rather than reactions to 'problems' waiting to be 'addressed' and 'solved', policies contain implicit problem representations that impose a particular stamp upon how an issue is understood. These problem representations rely upon socially produced meaning-systems, including expert knowledges, that have a range of effects: limiting what can be observed and discussed, eliciting forms of behaviour that encourage certain ways of being, and discursively shaping interventions that affect people's lives in the real. Such an approach encourages policy makers, planners and academic researchers to engage in reflexive analysis of policy proposals to identity aspects of a policy that may well subvert desired objectives.

\section{Notes}

1. The material in this case study draws upon Chapter 5 in Bacchi and Eveline 2010, Mainstreaming Politics: Gendering Practices and Feminist Theory, available free online from University of Adelaide Press at http://www.adelaide.edu.au/press

\section{LITERATURE}

- Bacchi, C. (1990): Same Difference: Feminism and Sexual Difference. Allen \& Unwin, Sydney. - Bacchi, C. (1999): Women, Policy and Politics: The construction of policy problems. Sage, London. - Bacchi, C. (2004): Gender/ing impact assessment: Can it be made to work? in: Journal of Interdisciplinary Gender Studies. Volume 9, Number 2, 93-111.

- Bacchi, C. (2005): Discourse, discourse everywhere: Subject "Agency" in Feminist Discourse Methodology, in: NORA (Nordic Journal of Women's Studies). Volume 13, Number 3, 198209.

- Bacchi, C. (2009a): Analysing Policy: What's the problem represented to be? Pearson Education, Frenchs Forest.

- Bacchi, C. (2009b): The issue of intentionality in frame theory: the need for reflexive framing, in: Lombardo, E., Meier, P. and Verloo, M. (eds): The Discursive Politics of Gender Equality: Stretching, bending and policymaking. Routledge, London and New York. 
. Bacchi, C. (2009c): Challenging the Displacement of Affirmative Action by Gender Mainstreaming, in: Asian Journal of Women's Studies. Volume 15, Number 4, 7-29.

- Bacchi, C. and Eveline, J. (2003): Mainstreaming and Neoliberalism: A Contested Relationship, in: Policy \& Society: Journal of Public, Foreign and Global Policy. Volume 22, Number 2, 119-143. - Bacchi, C. and Eveline, J. (2009): Gender Mainstreaming or Diversity Mainstreaming? The Politics of "Doing", in: NORA (Nordic Journal of Feminist and Gender Research). Volume 17, Number 1, 2-17.

- Bacchi, C. and Eveline, J. (2010): Mainstreaming Politics: Gendering Practices and Feminist Theory. University of Adelaide Press, Adelaide. Available free online.

- Beilharz, P. (1987): Reading Politics: Social Theory and Social Policy, in: Australian and New Zealand Journal of Sociology. Volume 23, Number 3, 388-406.

- Crawley, M. and O'Meara, L. (2002): Gender Proofing Handbook. NDP Gender Equality Unit, Dublin.

- Dean, M. (1999): Governmentality: Power and Rule in Modern Society. Sage, London.

- Dean, M. (2006): Governmentality and Powers of Life and Death, in: Marston, G. and McDonald, C. (eds) Analysing Social Policy: A Governmental Approach. Edward Elgar, Cheltenham.

- Eveline, J. (1994): The Politics of Advantage, in: Australian Feminist Studies, Special Issue: Women and Citizenship. Volume 19/Autumn), 129-54. - Eveline, J. and Bacchi, C. (2005): What are we mainstreaming when we mainstream gender?, in: International Feminist Journal of Politics. Volume 7, Number 4, 496-512.

- Foucault, M. (1972): The Archaeology of Knowledge. Trans. A. M. Sheridan Smith. Pantheon, New York.

- Foucault, M. (1991) [1968]: Politics and the Study of Discourse in: Burchell, G., Gordon, C. and Miller, P. (eds) The Foucault Effect: Studies in Governmentality. University of Chicago Press, University of Chicago Press.

- Foucault, M. (1994) [1981]: So is it Important to Think? In: Fabion, J. D. (ed.) Power: Essential Works of Foucault 1954-1984, vol. 3. Trans. R. Hurley and others. Penguin, London. . Foucault, M. (1997) [1984]: Polemics, Politics and Problematization, in: Rabinow, P. (ed.) Michel Foucault, Ethics: Essential Works of Foucault 19541984. Trans. L. Davis. New Press, New York. - Honkanen, K. (2008): Equality Politics out of the Subaltern, in: Magnusson, E., Rönnblom, M. and Silius, H. (eds) Critical Studies of Gender Equalities: Nordic dislocations, dilemmas and contradictions. Makadam Publishers, Göteborg. - McHoul, A. and Grace, W. (1993): A Foucault Primer: Discourse, Power and the Subject. Melbourne University Press, Melbourne.

- Osborne, K., Bacchi, C. and Mackenzie, C. (2008): Gender Analysis and Community Consultation: The Role of Women's Policy Units, in: The Australian Journal of Public Administration. Volume 67, Number 2, 149-160.

- Pavlich, G. (2001): The Art of Critique or How Not to be Governed Thus, in: Wickham, G. and Pavlich, G. (eds) Rethinking Law, Society and Governance: Foucault's Bequest. Cambridge University Press, Cambridge, UK.

- Petersen, A. (2003): Governmentality, Critical Scholarship, and the Medical Humanities, in: Journal of Medical Humanities. Volume 24, Numbers 3 and 4, 187-201.

- Plantenga, J. (2000): Gender Impact Assessment and the Employment Strategy: The Case of The Netherlands. External Report commissioned and presented to the European Commission. Available at: http://www2.umist.ec.uk/management/ewerc/publications/2000-2001.html

Accessed 16 November 2002.

- Rabinow, P. and Rose, N. (2006): Biopower Today, in: BioSocieties. Volume 1, 195-217.

- Rees, T. (1998): Mainstreaming Equality in the European Union: Education, Training and Labour Market Policies. Routledge, London.

- Shapiro, M. J. (1988): The Politics of Representation: Writing Practices, Photography and Policy Analysis. University of Wisconsin Press, Madison. - Simons, J. (1995): Foucault and the Political. Routledge, New York.

- Verloo, M. (2001): Another Velvet Revolution? Gender Mainstreaming and the Politics of Implementation, IWM Working Paper No. 5/2001. Institute of Human Sciences (IWM), Vienna.

- Verloo, M. (2005): Mainstreaming Gender Equality in Europe: A critical frame analysis approach, in: The Greek Journal of Social Research Volume 117, B', 11-34.

- Verloo, M. and Roggeband, C. (1996): Gender Impact Assessment: The Development of a New Instrument in The Netherlands, in: Impact Assessment. Volume 14, Number 1, 3-31.

- Yuval-Davis, N. (2006): Intersectionality and feminist politics, in: European Journal of Women's Studies. Volume 13, Number 3, 193-209. 


\section{SUMMARY}

Poststructuralism, Discource and Problematization: Implications for mainstreaming.

This article introduces a methodology, called 'what's the problem represented to be?' (WPR approach), that facilitates a form of poststructural policy analysis, and applies it to gender analysis procedures in Ireland and the Netherlands. In this methodology policies are understood as discursive practices, imposing specific shapes (called problem representations) on the 'problems' they purport to 'address'. A WPR approach to policy analysis in- volves identifying the underlying conceptual logics in these problem representations and evaluating them in terms of their implications or effects. It also alerts those involved in designing and implementing gender mainstreaming programs to their location within dominant conceptual frameworks and the subsequent need for a form of reflexive policy practice.

Carol Bacchi

Professor in Politics

University of Adelaide 